\title{
Spectrophotometric Determination of Glucosamine and Its Analogous Amino Sugars with $o$-Hydroxyhydroquinonephthalein and Palladium(II)
}

\author{
Takako Yamaguchi, Mayumi Inoue, Kanako MiYachi, Hiroshi Tominaga, and Yoshikazu Fujita ${ }^{\dagger}$ \\ Osaka University of Pharmaceutical Sciences, Nasahara, Takatsuki, Osaka 569-1094, Japan
}

\begin{abstract}
A simple and highly sensitive spectrophotometric method for the determination of glucosamine and its analogous amino sugars was established based on fading of the palladium(II)-o-hydroxyhydroquinonephthaleinhexadecyltrimethylammonium complex. In the determination of glucosamine, Beer's law is obeyed in the range of $0.02-$ $0.18 \mu \mathrm{g} \mathrm{ml}^{-1}$, with an effective molar absorptivity at $630 \mathrm{~nm}$ and the relative standard deviation being $8.4 \times 10^{5} \mathrm{dm}^{3} \mathrm{~mol}^{-1}$ $\mathrm{cm}^{-1}$ and $1.08 \%(n=10)$. This method is about 70-times more sensitive than the Elson-Morgan method. The method was successfully applied to the assay of glucosamine in actual samples.
\end{abstract}

(Received August 29, 2003; Accepted November 10, 2003)

Glucosamine, which is a component of proteoglycan, is found in and around the cells of the cartilage in people's joints, and is currently used for the treatment of degenerative joint disease in small animals, and represents a novel approach for the treatment of degenerative conditions. Also, glucosamine is considered to be a dietary supplement, and as such the content uniformity as well as the glucosamine products are rarely determined. Methods for analyzing glucosamine include spectrophotometry, ${ }^{1-8}$ spectrofluorometry, ${ }^{9,10}$ liquid chromatography ${ }^{11-13}$ and gas chromatography. ${ }^{14,15}$

On the other hand, glucosamine and its analogous amino sugars, such as mannosamine and galactosamine, have several donor atoms capable of metal complex formation and binding ${ }^{16,17}$ with copper(II), zinc(II), nickel(II), iron(III), cobalt(III) and so on. We have reported ${ }^{18-20}$ on simple and sensitive methods for various organic compounds based on the fading of a colored dye-metal complex. In the color reaction between $o$-hydroxyhydroquinonephthalein (QP) and palladium(II) (Pd(II)), we noticed that the color development of the QP-Pd(II) complex was interfered with by small amounts of amino sugars, such as glucosamine. We, therefore, speculated that a method which would utilize fading of a QP-Pd(II) complex in the presence of an amino sugars would serve as a simple and highly sensitive determination of amino sugars. Here, we report on a spectrophotometric method for the determination of glucosamine and its analogous amino sugars based on the fading of a QP-Pd(II) colored complex.

\section{Experimental}

Reagents and apparatus

A stock solution $\left(1.0 \times 10^{-2} \mathrm{M}, 1 \mathrm{M}=1 \mathrm{~mol} \mathrm{dm}^{-3}\right)$ of

A part of this work was presented at the 121st Annual Meetings of the Pharmaceutical Society of Japan, Sapporo, 2001.

$\dagger$ To whom correspondence should be addressed.

E-mail: fujitay@gly.oups.ac.jp
D-glucosamine hydrochloride (Wako Pure Chem. Co. Ltd.) in water, and the working solution was prepared by suitable dilution of this stock solution as required. A solution $\left(5.0 \times 10^{-4}\right.$ M) of palladium(II) was prepared from a stock solution (Wako Pure Chem. Co. Ltd., $1000 \mu \mathrm{g} \mathrm{l}^{-1}$ ) by dilution with water. A solution of QP, which had been synthesized according to a method described in the literature,,$^{21}$ was prepared in a $1.0 \times 10^{-3}$ $\mathrm{M}$ methanol solution containing one drop of hydrochloric acid. A $1.0 \times 10^{-2} \mathrm{M}$ aqueous solution of hexadecyltrimethylammonium chloride (HTAC, Tokyo Kasei Kogyo Co.) was prepared by dissolving HTAC purified by recrystallization in water. A buffer solution of $\mathrm{pH} 7.5$ was made by mixing appropriate amounts of a $0.1 \mathrm{M}$ potassium dihydrogenphosphate solution and a $0.1 \mathrm{M}$ disodium hydrogenphosphate soluton. Reagentgrade chemicals were used throughout. Pure water was prepared by purifying deionized water with Milli-Q Labo system just before use.

A Shimadzu spectrophotometer (Model UV-160) with 1.0-cm matched silica cells was used for an absorbance measurement. The $\mathrm{pH}$ measurements were made with a Horiba (F-11) $\mathrm{pH}$ meter in combination with a calomel glass electrode.

\section{Standard procedure for the determination of glucosamine}

The following components were mixed in a $10-\mathrm{ml}$ volumetric flask: a solution containing $0.2-1.8 \mu \mathrm{g}$ of glucosamine, $0.6 \mathrm{ml}$ of a $5.0 \times 10^{-4} \mathrm{M} \mathrm{Pd}(\mathrm{II})$ solution, $1.5 \mathrm{ml}$ of a $1.0 \times 10^{-2} \mathrm{M}$ HTAC solution, $2.5 \mathrm{ml}$ of the buffer solution and $0.8 \mathrm{ml}$ of a 5.0 $\times 10^{-4} \mathrm{M}$ QP solution. The mixture was diluted to $10 \mathrm{ml}$ with water, transferred into a test tube, mixed well and kept at $50^{\circ} \mathrm{C}$ for $30 \mathrm{~min}$. After the solution had been cooled in water to room temperature, the difference in the absorbance $(\Delta A)$ between the resultant solution and a reagent blank solution prepared under the same conditions was measured at $630 \mathrm{~nm}$ against water.

\section{Results and Discussion}

Optimization of reaction variables

In order to examine the utility of a method for the 


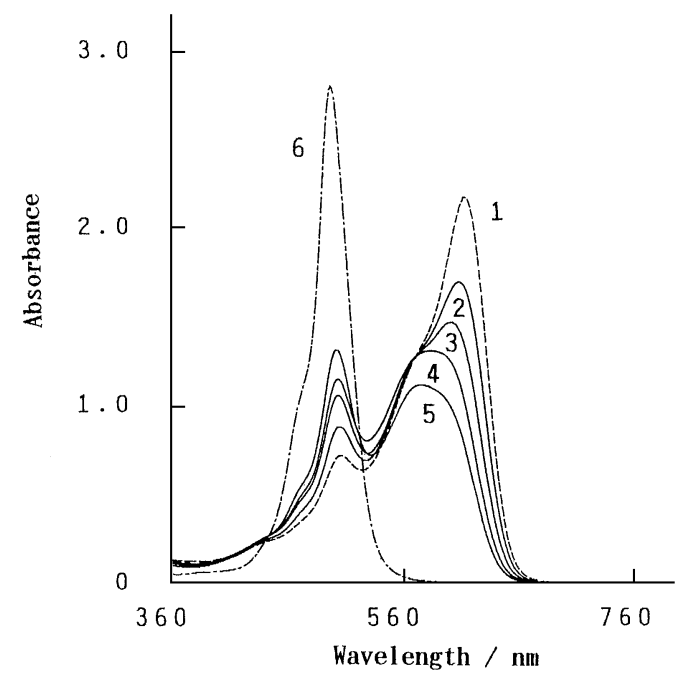

Fig. 1 Absorption spectra of QP-Pd(II) and QP solutions in the presence of glucosamine. $[\mathrm{Pd}(\mathrm{II})]=3.0 \times 10^{-5} \mathrm{M} ;[\mathrm{QP}]=4.0 \times 10^{-5}$ $\mathrm{M} ;[\mathrm{CTAC}]=1.5 \times 10^{-3} \mathrm{M} ; \mathrm{pH}=8.0$. Curves $1,2,3,4$ and 5 for $\mathrm{QP}-$ $\mathrm{Pd}$ (II) solutions (glucosamine concentration $(\mathrm{M})$ : curve $1=0$; curve 2 $=1.0 \times 10^{-6} ;$ curve $3=2.0 \times 10^{-6}$; curve $4=3.0 \times 10^{-6}$; curve $5=4.0$ $\left.\times 10^{-6}\right)$. Curve 6, QP solution. Reference, water.

determination of glucosamine based on fading of a dye-metal colored complex, the color reactions between various dyes and metal ions were studied by comparing the situations in the presence of glucosamine. The effect of metal ions on the reaction system was investigated. Only palladium(II) was effective among various metal ions tested: palladium(II), copper(II), zinc(II), nickel(II), cobalt(II), iron(III), manganese(II) and molybdenum(VI). Next, the dyes ${ }^{22}$ were studied by using QP, $o$-sulfophenylfluorone (SPF), salicylfluorone (SF), phenylfluorone (PF), p-carboxyphenylfluorone (PCPF), Pyrogallol Red, Pyrocatechol Violet, Xylenol Orange and 4-(2-pyridylazo)resorcinol. These dyes could be arranged in the following order with respect to the sensitivity: $\mathrm{QP}>\mathrm{SF}>\mathrm{SPF}>\mathrm{PF}>\mathrm{PCPF}>>$ the others $\approx 0$.

The effect of the $\mathrm{pH}$ on the reaction was examined by using various buffer solutions, such as $0.1 \mathrm{M}$ potassium dihydrogenphosphate/0.1 M disodium hydrogenphosphate, 0.1 $\mathrm{M}$ citric acid/0.1 M disodium hydrogenphosphate, $0.1 \mathrm{M}$ potassium dihydrogenphosphate/0.05 $\mathrm{M}$ borax, $0.1 \mathrm{M}$ hydrochloric acid/0.1 M tris(hydroxymethyl)aminomethane and $0.1 \mathrm{M}$ hydrochloric acid/0.1 M sodium 5,5-diethylbarbiturate solutions. The best $\mathrm{pH}$ range was from 6.8 to 8.2 by using 2.5 $\mathrm{ml}$ of $0.1 \mathrm{M}$ potassium dihydrogenphosphate/0.1 M disodium hydrogenphosphate buffer solution.

The effect of the amounts of $\mathrm{QP}$ and $\mathrm{Pd}(\mathrm{II})$ on $\Delta A$ was examined while maintaining a fixed final concentration of glucosamine $(0.90 \mu \mathrm{g})$. The results indicated that the molar ratio of $\mathrm{QP}$ to $\mathrm{Pd}(\mathrm{II})$ should be greater than equimolar. Accordingly, all further work was carried out with $3.0 \times 10^{-5} \mathrm{M}$ $\mathrm{Pd}$ (II) and $4.0 \times 10^{-5} \mathrm{M}$ QP solutions in relation to the determination limit of glucosamine and the absorbance of a QPPd(II) solution.

In order to stabilize the color development and to enhance the sensitivity, the effects of different surfactants were examined: cationic (HTAC, hexadecylpyridinium chloride, zephiramine, stearyltrimethylammounium chloride), nonionic (Tween 20, Triton X-405, polyvinylalcohol, Brij 35), anionic (sodium dodecylsulfate, sodium di(2-ethylhexyl)sulfosuccinate) and amphoteric (Amphitol 24B, Swanol AM-101). The use of
Table 1 Sensitivities and reproducibilities of the proposed method

\begin{tabular}{lcc}
\hline \multicolumn{1}{c}{ Substance } & $\varepsilon / \mathrm{dm}^{3} \mathrm{~mol}^{-1} \mathrm{~cm}^{-1}$ & $\mathrm{RSD}^{\mathrm{a}}, \%$ \\
\hline Glucosamine & $8.4 \times 10^{5}$ & 1.08 \\
Mannosamine & $5.7 \times 10^{5}$ & 1.48 \\
Galactosamine & $5.2 \times 10^{5}$ & 1.36 \\
UDP- $N$-Acetyl-D-glucosamine & $4.0 \times 10^{4}$ & $-^{\mathrm{b}}$ \\
Streptomycin & $2.5 \times 10^{5}$ & $-^{\mathrm{b}}$ \\
\hline
\end{tabular}

a. Mean of 10 determinations.

b. Undetermined.

HTAC was the most effective in terms of sensitivity.

The color development in this reaction system did not occur instantaneously at room temperature. Thus, the effects of the incubation temperature and time were examined at 40, 50 and $60^{\circ} \mathrm{C}$. A maximum and constant $\Delta A$ value was obtained by heating at $50^{\circ} \mathrm{C}$ for $30 \mathrm{~min}$, followed by cooling in water to room temperature. The $\Delta A$ value remained constant for at least $3 \mathrm{~h}$ after the solution had been cooled to room temperature.

Figure 1 shows the absorption spectra of QP-Pd(II) in the presence or absence of glucosamine and QP solutions.

\section{Calibration curve}

A calibration curve for glucosamine was constructed by the standard procedure. A good linear relationship was observed over $0.02-0.18 \mu \mathrm{g} \mathrm{ml}^{-1}$ of glucosamine. The effective molar absorptivity $(\varepsilon)$ was calculated from the slope of the calibration graph to be $8.4 \times 10^{5} \mathrm{dm}^{3} \mathrm{~mol}^{-1} \mathrm{~cm}^{-1}$. The relative standard deviation (RSD) for ten runs of $0.90 \mu \mathrm{g}$ of glucosamine was $1.08 \%$. The calibration curves for other amino sugars and related compounds were also constructed under the optimum conditions. As shown in Table 1, the sensitivities of mannosamine and galactosamine were somewhat low compared with that of glucosamine. The reaction between proteoglycans, such as hyaluronic acid and chondroitin sulfate, and the QP$\mathrm{Pd}(\mathrm{II})$ solution were not studied in the present work. This method is about 70-times more sensitive than the Elson-Morgan method, ${ }^{1,2}$ and gives excellent reproducibilities.

\section{Interference of foreign substances}

The interference from various foreign substances on the determination of glucosamine was examined. Inorganic ions, such as sodium, potassium, ammonium, calcium, magnesium, chloride, bromide, nitrate, sulfate, and phosphate, did not noticeably affect the accuracy of the determination of glucosamine, even when these ions were present in large excess amounts compared with that of glucosamine. A fairly large error appeared in the presence of copper(II), iron(III), zinc(II) and glucuronic acid. Organic substances, such as glucose, glycine, caffeine, urea, ascorbic acid and methylcellulose, interfered very little. The results are summarized in Table 2.

\section{Application}

The proposed method was applied to the determination of glucosamine in commercial dietary supplements (tablets). The contents of the tablets were accurately weighed and ground in a mortar to a fine powder. The requiste volume of powder was weighed, transferred into a 100-ml volumetric flask, diluted to the mark with water and filtered. An appropriate amount of the sample solution was taken and assayed according to the standard procedure. The accuracy of the proposed method was checked by a thorough replicate analysis of each spiked sample. Neat standards were prepared under the same conditions. The 
Table 2 Effect of foreign substances on the assay of glucosamine

\begin{tabular}{lccc}
\hline \multicolumn{1}{c}{ Substance } & $\begin{array}{c}\text { Added } \\
\text { (Substance/ } \\
\text { glucosamine) }\end{array}$ & $\begin{array}{c}\Delta A \\
\text { at } 630 \mathrm{~nm}\end{array}$ & $\begin{array}{c}\text { Recovery, } \\
\%\end{array}$ \\
\hline $\mathrm{NaCl}$ & $1.0 \times 10^{2}$ & 0.432 & 100.0 \\
$\mathrm{~K}_{2} \mathrm{SO}_{4}$ & $1.0 \times 10^{2}$ & 0.432 & 100.0 \\
$\mathrm{CH}_{3} \mathrm{COONa}$ & $1.0 \times 10^{2}$ & 0.432 & 100.0 \\
$\mathrm{NH}_{4} \mathrm{Cl}$ & $1.0 \times 10^{2}$ & 0.432 & 100.0 \\
$\mathrm{NaNO}_{3}$ & $1.0 \times 10^{2}$ & 0.432 & 100.0 \\
$\mathrm{KBr}$ & $1.0 \times 10^{2}$ & 0.432 & 100.0 \\
$\mathrm{Sodium}$ citrate & $1.0 \times 10^{2}$ & 0.432 & 100.0 \\
$\mathrm{Mg}(\mathrm{II})$, chloride & $1.0 \times 10^{2}$ & 0.432 & 100.0 \\
$\mathrm{Ca}(\mathrm{II})$, chloride & $1.0 \times 10^{2}$ & 0.432 & 100.0 \\
$\mathrm{Cu}(\mathrm{II})$, nitrate & 1.0 & 0.506 & 117.1 \\
$\mathrm{Fe}(\mathrm{III})$, sulfate & 1.0 & 0.450 & 104.2 \\
$\mathrm{Zn}(\mathrm{II})$, chloride & 2.0 & 0.455 & 105.3 \\
$\mathrm{Glucuronic}$ acid & 1.0 & 0.461 & 106.7 \\
Pyridoxine-HCl & $2.0 \times 10$ & 0.432 & 100.0 \\
Glycine & $2.0 \times 10$ & 0.432 & 100.0 \\
Ascorbic acid & $1.0 \times 10^{2}$ & 0.432 & 100.0 \\
Caffeine & $1.0 \times 10^{2}$ & 0.432 & 100.0 \\
Glucose & $1.0 \times 10^{2}$ & 0.432 & 100.0 \\
Lactose & $1.0 \times 10^{2}$ & 0.432 & 100.0 \\
Urea & $1.0 \times 10^{2}$ & 0.432 & 100.0 \\
Methylcellulose & $1.0 \mathrm{mg}$ & 0.432 & 100.0 \\
\hline
\end{tabular}

[glucosamine $]=5.0 \times 10^{-7} \mathrm{M} ;[\mathrm{Pd}(\mathrm{II})]=3.0 \times 10^{-5} \mathrm{M} ;[\mathrm{QP}]=4.0 \times$ $10^{-5} \mathrm{M} ;[\mathrm{HTAC}]=1.5 \times 10^{-3} \mathrm{M} ; \mathrm{pH}, 8.5$; reference, water.

recoveries of added quantity were about $102-103 \%$. This indicates that the proposed method gives accurate results. These results are given in Table 3 .

Composition of the colored complex and reaction mechanism In order to clarify the reaction mechanism, the composition of the colored complex was studied by Job's method of continuous variation and the molar ratio method. The $\mathrm{Pd}(\mathrm{II})-\mathrm{to}-\mathrm{QP}$ ratio and the $[\mathrm{Pd}(\mathrm{II}) / \mathrm{QP}-$ to-HTAC] ratio were $1: 1$ and $1: 1$, respectively. On the other hand, the glucosamine-to-Pd(II) ratio was 1:1 in the presence and absence of QP. It was found that the reaction rate between glucosamine and $\mathrm{Pd}(\mathrm{II})$ was much faster than between $\mathrm{QP}$ and $\mathrm{Pd}(\mathrm{II})$, by tracing the absorption spectrum of the $\mathrm{Pd}(\mathrm{II})$ solution. The experimental results imply that glucosamine, which has ligands containing oxygen and nitrogen atom as donor atoms, reacted with $\mathrm{Pd}(\mathrm{II})$ to give the glucosamine-Pd(II) complex in the first step, followed by the formation of QP-Pd(II)-HTAC [1:1:1] complex.

In conclusion, a simple and highly sensitive spectrophotometric method for glucosamine and its analogous amino sugars was established with QP and Pd(II) in a HTAC micellar medium. This procedure is based on a decrease in the absorbance of the QP-Pd(II)-HTAC ternary complex solution in the presence of amino sugars, such as glucosamine. The reaction mechanism was examined in this study, and an amino sugar-Pd(II) complex was formed as the result of a competitive reaction between an amino sugar and QP to $\mathrm{Pd}(\mathrm{II})$ in the first step. A residual $\mathrm{Pd}(\mathrm{II})$ subsequently reacted with $\mathrm{QP}$ in the presence of HTAC to give the ternary complex of Pd(II)-QPHTAC [1:1:1]. The sensitivity $\left(\varepsilon=8.4 \times 10^{5} \mathrm{dm}^{3} \mathrm{~mol}^{-1} \mathrm{~cm}^{-1}\right)$ of the proposed method was much more sensitive than that of other spectrophotometric methods. The proposed method, owing to no need for solvent extraction, should be useful for a simple and highly sensitive determination of glucosamine in real samples.
Table 3 Application of this method to determine glucosamine in a dietary supplement

\begin{tabular}{ccccc}
\hline \multirow{2}{*}{ Sample $^{\mathrm{a}}$} & \multicolumn{2}{c}{ Content/mg } & & \\
\cline { 2 - 3 } & $\begin{array}{c}\text { Nominal } \\
\text { amount }\end{array}$ & $\begin{array}{c}\text { Present } \\
\text { method }\end{array}$ & $\begin{array}{c}\text { RSD }^{\mathrm{b}}, \\
\%\end{array}$ & $\begin{array}{c}\text { Recovery } \\
\%\end{array}$ \\
\hline $\mathrm{A}$ & 375.1 & 365.5 & 1.20 & 102.2 \\
$\mathrm{~B}$ & 500 & 502.4 & 1.25 & 102.8 \\
\hline
\end{tabular}

a. Sample A (glucosamine hydrochloride): Tablet (per 1 Tab.) also contained dextrin, cellulose, methylcellulose, stearic acid, glycerol and silicon dioxide, stidine. Sample B (glucosamine sulfate): Tablet (per $1 \mathrm{Tab}$.) also contained ascorbic acid, methylsulfonyl methane, calcium and chondroitin sulfate.

b. Mean of 5 determinations.

c. Glucosamine taken, $0.45 \mu \mathrm{g}$.

\section{References}

1. M. Pesez and J. Bartos, "Colorimetric and Fluorimetric Analysis of Organic Compounds and Drugs", 1974, Marcel Dekker, Inc., New York.

2. L. A. Elson and W. J. T. Morgan, Biochem. J., 1933, 26, 1824

3. W. J. T. Morgan and L. A. Elson, Biochem. J., 1934, 28, 988.

4. E. Sawicki, T. R. Hauser, T. W. Stanley, and W. Elbert, Anal. Chem., 1961, 33, 93.

5. J. T. Galambos and R. Shapira, Anal. Biochem., 1966, 15, 334.

6. S. Ogawa, M. Morita, A. Nakajima, and T. Yoshida, Yakugaku Zasshi, 1968, 88, 866.

7. A. Nakamura, M. Maeda, T. Kinoshita, and A. Tsuji, Chem. Pharm. Bull., 1969, 17, 770.

8. A. Tsuji, T. Kinoshita, and M. Hoshino, Chem. Pharm Bull., 1969, 17, 1505.

9. A. Tsuji, T. Kinoshita, and M. Hoshino, Seikagaku, 1968 , 40, 495

10. M. Maeda, T. Kinoshita, and A. Tsuji, Anal. Biochem., 1970, 38, 121.

11. W. Chen and R. Y. Y. Chiou, J. Agric. Food Chem., 1999, 47, 1999.

12. Z. M. Liang, J. Leslie, A. Adedowale, M. Ashraf, and N. D. Eddington, J. Pharm. Biomed. Anal., 1999, 20, 807.

13. H. Yokota, K. Mori, H. Yamaguchi, H. Kaniwa, and N Saisho, J. Pharm. Biomed. Anal., 1999, 21, 767.

14. P. A. Biondi, F. Manca, A. Negri, G. Tedeschi, and C. Secchi, J. Chromatogr., 1989, 467, 315.

15. A. Sonesson, K. Bryn, E. Jantzen, and L. Larsson, $J$. Chromatogr., Biomed. Appl., 1989, 79, 1.

16. M. Maeda, T. Kinoshita, and A. Tsuji, Tetrahedron Lett., 1968, 30, 3407.

17. Y. Ye, J. M. Hu, Y. E. Zeng, H. Y. Shen, Z. F. Le, and J. Chen, Fenxi Ceshi Xuebao, 1998, 17, 24.

18. Y. Fujita, I. Mori, M. Toyoda, and T. Matsuo, Anal. Sci., 1994, 10, 827.

19. Y. Fujita, I. Mori, and T. Matsuo, Anal. Sci., 1998, 14, 1157.

20. Y. Fujita, I. Mori, and T. Yamaguchi, Anal. Sci., 2002, 18, 981.

21. C. Liebermann, Chem. Ber., 1901, 34, 2299.

22. H. Sano, Bull. Chem. Soc. Jpn., 1958, 31, 974. 